\title{
IMPACT OF INNOVATIVE LEARNING ENVIRONMENT BASED ON RESEARCH ACTIVITIES ON SECONDARY SCHOOL STUDENTS' ATTITUDE TOWARDS RESEARCH AND THEIR SELF-EFFICACY
}

\author{
Dr. Kaltham A. Al-Ghanim \\ PhD Sociology, Specific Field Sociology of Development \\ Social sciences Department, Qatar University, Qatar \\ Dr. Mariam A. Al-Maadeed \\ $\mathrm{PhD}$ Materials Science, Specific Field Polymers Characterizations \\ Center for Advanced Materials (CAM), Qatar University, Qatar \\ Dr. Noora Jabor Al-Thani /Assistant Prof. \\ PhD Biophysics, Center for Advanced Materials (CAM), \\ Qatar University, Qatar
}

\begin{abstract}
Advanced and free learning environment coupled with the creative learning activities is assumed to be a motivational variable. In the present study, we applied an innovative learning strategy involving students in order to achieve positive impact on their attitude towards science, desire to learn science and future career choices. The study experiment was focused on enhancing the research skills of the students; apply knowledge for solving real world problems, positively changing the students' attitude towards science, raising students' self-efficacy and enhance positivism toward science related subjects. This research assumes that if the attitude and perception of post-secondary students is changed and made positive about science, then they might choose to study related science subjects forexample, mathematics, engineering and science at university level studies. Therefore, it will also impact students' career choices after university studies and they might enter scientific careers. Our study focused on evaluating various changes in the attitude, desire and self-efficacy of participating students when traditional instruction is replaced through the innovative learning environment. A total of 120 students participated in our experiment where researchers assisted students to experience hands on different research activities. Pre and posttest were used to evaluate the change in students' attitude and desire towards science, knowledge and self-efficacy. The study
\end{abstract}


results have shown that significant changes in the performance of students' for-example, student noticed positive attitude towards their own research abilities, desire to learn science, self-efficacy, learning and career choices. However, results did not show any differences based on gender as such.

Keywords: Career choice, desire to learn, innovative learning environment, self-efficacy, student attitude

\section{Introduction}

The emergence of developmental projects coupled with the globalization of the labour market has led to the emergence of newer economic sectors. Such newly emerging economic sectors have different requirements in terms of the workforce. Since these new sectors, demand workforce having skillset which is interdisciplinary in nature and also include technical subspecialities. Considering the occurrence of these changes, in Arab region especially Gulf states have recognized the importance of knowledge-based economy. This is quite evident by the active planning initiatives undertaken by Gulf nations for making transition to the knowledge-based economy.

However, at present the gulf countries are facing the shortage of skilled labour force. Furthermore, this problem is aggravated due to shortcomings in their present educational setup. The most remarkable challenge is the existence of the mismatch between the labour market requirements and the educational outcomes. The present educational sector is proving to be incapable in adapting itself with the developments occurring in the labour market leading to the failure in producing the specialized workforce and scientific professionals that are much needed by the industry.

First and foremost, the major problem faced by the economy and labour market of the Arab region is the continuous decline in the number of educational outcomes of the micro scientific disciplines. Secondly as mentioned previously, the Arab educational curricula is proving to be insufficient in providing students with the skills matching the developments occuring in the existing labour market (as indicated by the Arab knowledge report 2010/2011). Such a situation is significantly contributing towards hindering the economic development of the Arab countries. In this regard, the Arab knowledge report (2010/2011) suggests education policy makers to take important and necessary steps for changing the existing educational curricula in terms of content and methodologies. It stresses on having an educational curricula that has a professionally orientation. The new educational curricula should provide upscale and sophisticated knowledge that corelates with the requirements of the constantly changing trends of labour market. Additionally, the provided knowledge should be applicable 
beyond the boundaries of national economy meeting the demands of the global labour market ${ }^{3}$.

Trend in International Mathematics and Science Study (TIMSS ) results revealed that on average the grade 8 students in the Arab region attain significantly lower scores than their counterparts in the United States (Michael et al. 2011). However in context to Arab region, TIMSS results also reflect that female students are better in science than males (Timms201: 167). On the other hand, results from United States presents an opposite view where males are better than females in science. On the general note, it can be concluded that Arabic young generation is less likely to major in disciplines related to mathematics and science when they reach higher education.

The present study has been conducted on the students in the Qatar University. The aim of the study was to test and explore the capabilities of a non-traditional learning strategy in improving the learning performance of the students. Furthermore, applicability of this learning strategy will also be tested with regards to fostering the sense of self-efficacy and generating positive attitude among students towards science. The purpose of this study is to explore, test and evaluate the impact of practing innovative learning environment with students on their attitude towards science and possible career choices. In this study experiment, a non-traditional learning strategy was practiced with students who were exposed in new ways of learning and closely worked with researchers on different assigned problems.

\section{Theoretical background "Self-Efficacy"}

The sense of self efficacy reflects one's belief or confidence of experience success. The substanial body of research has recognised the positive perceptions in context to self-efficacy as one of the major determinants while making career choices. Albert Bandura (1977) explained the learning process in the terms of the causual conditions affecting it from the individual perspective. In this regard, he discussed the effects of the educational curriculum on the development of the psychologcal and cognitive aspects of the students. From the viewpoint of social cognitive theory, Bandura (Bandura, 1977:191-215) also pointed out the factors causing behavioral changes as the sense of self-efficacy can be acquired through the means of the education. Furthermore, the explainations of the

3 - The statistics which included in the Arab Knowledge Report 2010/2011, preparing future generation for the knowledge society, showed high unemployment rate among Arab youth, these facts showed also by, Arab Human Development Reports 2002 -2012 which indicated that there is still a high rate of the Illiteracy between the young generation beside inability to provide the required investment to advance the economies of the Arab countries. 
learning process stress that the preceived self-efficacy reflects individual's attitudes, abilities and cognitive skills (Bandura, 1977:191-215). Over the period of three decades beginning in 1977, Pandora developed a cognitve theory that explains the different social and individual factors effecting the human choices and their ability to judge things. The proposed cognitive theory also uses the concept of self-efficacy as the main factor that enhances individual's perceptions about their abilities and their chances of success. Furthermore, Pandora (xx) states that the perceived self-efficacy is reflected in the human behaviour which contributes in scrutinizing the available options and determining the ultimate career choices. Personal self-efficacy can be derived from four principal sources of information: (i) performance accomplishments, (ii) vicarious experience, (iii) verbal persuasion and (iv) physiological states (Bandura, A. 1977:pp. 191-215).

Self-efficacy beliefs influence motivational and self-regulatory processes in several ways. In other words, they influence the choices people make and the courses of action they pursue. Most people engage in tasks in which they feel competent and confident and avoid those in which they do not (Frank Pajares,1997:1-49). For example, in certain situations students might find that spending of skillful efforts might not be sufficient for bringing the desired outcomes. In such cases, students may possess necessary skills and high self-efficacy required for achieving the desired outcomes, but they may not progress forward because of lack of necessary incentives (Ibid).

According to Bandura, self-efficacy stands for the judgment of one's capability to accomplish a certain task. Furthermore, Bandura also argues that self-beliefs of self-efficacy play a key role in the self-regulation of motivation. Additionally, people who are motivated themselves can guide their own actions based on their own beliefs about what they can do and their own thoughtfulness (Bandura, A.1994:71-81).

A strong sense of academic efficacy can directly enhance the individual's perceptions of self-efficacy regarding future career choices. Additionally, academic aspirations and scholastic achievements also play a mediating role for the enhancement of self-efficacy perceptions. Selfappraisal of the occupational efficacy is important factor for generating willingness to engage in the careers requiring high-level cognitive skills. In this regard, perceptions regarding social and self-regulatory efficacy operate as the supplementary personal resources influencing the dimension of selfappraisal in context to occupational self-efficacy. Therefore, social boldness and efficacy required for curbing transgressiveness are insufficient for ensuring occupational attainments (Bandura A, Barbaranelli C, Caprara GV, Pastorelli C .2001: 191). So from this viewpoint, it can be seen that selfefficacy can be influenced by social context and other factors that allow changing of human behaviour. Such factors can include daily experiences 
embedded in some social environment, education, teachers, equipment and training. Additionally, the theory of Pandora opened up opportunities for examining the role of cultural factors in this regard. According to sociological perspective, the cultural factors can be formulated by social context and individual's beliefs and attitudes

\section{"Negative attitude towards Science"}

Upon reviewing the important published literature on the subject over the past 20 years, it was found that the presence of different factors within the classroom environment and educational activities that affect students' attitude and interest towards studying science subjects (Jonathan Osborne, Shirley Simon \&Sue Collins, 2003). Additionally, these studies have argued that the continuous decline in students' numbers choosing to study science at their point of choice requires scientific examination. Furthermore, this scientific examination should be focussed on examination of various factors that influence the students' attitude towards studying science and related subject. Previous research has found that student attitude towards studying science is affected due to number of reasons including gender, age, curriculum, teachers, cultural and demographics related variables (Ibid).

One of the most common problem faced by the student community is their negative attitude towards science discipline in general. The traces regarding the existence of this negative attitude towards science was identified long back on 1971 when McNarry et al. conducted a study on the secondary school students in United States while examining the factors affecting their choices of education and career. The study grounded the presence of negative attitude within social context of the students (L. R. McNarry, S. O'Farrell ,1971: pp. 1060-1061 ). Additionally, McNarry et al. (1971) recommended putting additional efforts towards changing the existing attitude of the students by positively enhancing the awareness towards science at the societal level.

The empirical studies conducted in the last few decades reveal that the importance of the internal factors such as personal determinants of the academic achievement and success has also grabbed the attention of scholars. A recent empirical study emphasizes that the students' perceptions about their teachers' goals and peer's goal orientation has a strong influence on their academic achievement and career choices. Dana Vedder-Weiss et al. (2012) stated that school culture also has a significant impact on the students' motivation in addition to teachers and classtroom environment. The empirical study conducted on 13,985 students of 15 years of age from 431 schools across Canada examined effects of (i) students' motivations regarding learning science, (ii) beliefs towards science and (iii) instructional practices specific to science on their achievements in science as a discipline (Areepattamannil, S., Freeman, J. G., \& Klinger, D. A, 2011). The study 
results revealed the existence of only $8 \%$ variance regarding science achievements between the schools. On the other hand, 92\% of variance was found among the students within the schools. Additionally, the study also revealed that instructional practices involving hands-on sessions, motivational beliefs such as self-efficacy and self-concept aspects such as enjoyment in learning science has substantial positive predictive impact on the science achievement. On the contrary, it was also found that general interest in science has negative predictive effect on science achievement when compared to other contextual variables.

\section{"Status Attainment"}

The studies on status attainment suggest that the teenage aspirations are subject to frequent changes. Diverse theoretical and empirical traditions view aspirations as having a trajectory of their own irrespective of theme being considered such as "over ambition", "cooling out", the process of "contest mobility" or the need for "vocational realism" (Jerry A. Jacobs, David Karen and Katherine McClelland: 610). This conclusion has also been emphasized by the recent studies which indicate that the differential childhood socialization may be less important than actual experiences at school and work for the formulating student's aspirations and career choices (Ibid). In this regard, Osborne et al. (2003) also indicate that the students' attitudes are influenced by deferent factors such as: gender, teachers, curricula, and other socio-cultural variables. Furthermore, the literature also points out the importance of gender and quality of teaching in the formulation of students' attitudes. From the perspective of quality of teaching, we argue that there is a great need of research aimed at investigating and highlighting those aspects of teaching science that makes the discipline of science engaging for the pupils. The available research on human motivations also provides useful pointers regarding the kinds of classroom activities and environment that can enhance the students' interest in studying science (Ibid). Moreover, there are variety of factors that have a great influence on students' decisions regarding career and their attitudes towards science (.E. Myburgh, 2005: 46). For example, family or advice given by their parents, relatives, friends and school teachers. Additionally, the undertaken teaching and learning strategies along with the equipment used during the process also impact the students' attitude (Eylem YILDIZ, Ercan AKPINAR, Bülent AYDOĞDU1, Ömer ERGIN,2006,2-18).

The previous studies reveal that for both men and women instrumental attributes have a considerably stronger positive relationship with career decision-making and self-efficacy than other independent variables. Furthermore, there is a significant impact of interaction between internality and instrumentality on career decision-making. However, the existing studies on cross-culture, mixed-cultural populations (Myburgh, 
2005) in addition to the ones dealing with Arab population (Abdalla, 1988, 1991; Gaad, 2004) ${ }^{4}$ face some deficiencies. They fail to address the results and implications of the interactions between: (i) internality with self-esteem and (ii) instrumentality with self-esteem in context to Arab socio-politics. This effect has been shown to be especially strong in females (McDonald \& Jessell, 1992) ${ }^{5}$, and even more so for women in Arabic cultures (Abdalla, 1991) ${ }^{6}$.

Based on the above theoretical discussions it can be concluded that students' attitudes and self-efficacy are the major factors determining their career choices. Therefore, their attitudes towards science and career choices have a strong influence on their decisions to study certain disciplines and undertake specializations in some areas such as micro ones.

\section{Educational Structure, Economy and Labour Market in Qatar}

The secondary education plays a crucial role in the educational system of all societies. The main reason could be its structure as it bridges the gap between the primary and higher education. Furthermore, its importance can also be understood from the perspective of the age-group of the students it caters. It plays a significant role in shaping the human beings during the teenager years which are most tender years of life due to its placement between the childhood and adulthood. Furthermore, secondary school is an important phase for preparing young people for making decisions regarding their future career choices. In this regard, World Bank report (2005) indicated that the investment in the secondary education has highest economic returns not only for the individuals but also for the society. However, it can only have a significant positive impact if it is capable of guiding the students in developing the skills related to analytical and systematic problem solving and thinking.

At present the Qatar society is undergoing economic transition. It is making a transition to knowledge-based economy with the ultimate of goal of building a strong industrial sector by 2030. This is an ambitious vision that would need substantial financial investment and technology. Additionally, it also requires human and social capital coupled with the stimulating cultural context. Qatar has made some progress in this regard but still needs considerable efforts for overcoming these challenges and achieving the desired targets.

Currently Qatar is experiencing financial boom due to the high oil prices and its rapidly growing share in exporting gas. However at the same time, it experiences problems owing to its small population. In order to overcome the problem of small workforce Qatar opened its doors to foreign labor, which resulted in flooding of migrant workers from different countries. As a result of these conditions, the natives of Qatar acquired a minority position in their own country. According to the Labor Survey 
Statistics Authority (2011) the Qatari population represents only 6\% of the total workforce where majority of the employers work in the government sector (Ibid: Tables: 19, 66). As per Ibid (Ibid: Tables: 19, 66) the Qatari workforce represents about 32\% of the total economic force of Qatar where $66 \%$ are males and $34 \%$ are the females. Furthermore, $60 \%$ of the national labor force is employed in clerical occupations while only $19 \%$ of them are in education and technical occupations. At the same time, statistics also indicate that $46.7 \%$ of women workforce in the government sector is also engaged in the clerical.

The concentration of the national workforce in the public sector and in the clerical positions reflects the outcomes of the educational setup of the past decades. Moreover, from the last 15 years secondary and tertiary education is witnessing decline in the number of students studying mathematics and science (ee: Ziad Said, 2011, figure 1 in the appendix). Considering the aforementioned situational facts, it can be assumed that Qatari society is facing a tough challenge in preparing the generations for achieving the national goals. For example, inefficiency of the mainstream educational setup to adapt the existing curriculum to resolve following problems: (i) the problem of student dropout especially the male counterparts from the secondary and higher education, (ii) motivating the students to innovate, (iii) generating interest among students towards scientific disciplines and (iv) producing professionals meeting the requirements of future labor market. In addition to deficiencies in the educational setup, the parenting styles and various socio-cultural values also complicate the educational process.

The increased efforts are being made for diversifying the education sector. For example, Qatari government is making efforts to initiatives for overcoming the challenges by allocating more resources and investments for the human development projects. Especially, for developing the education system and the research sector for preparing present Qatari citizens and the future generations for meeting the demands of the labor market in terms of the knowledge and skills. In this regard, the educational policy reforms have also been introduced in 2003 under the name "Education for New Era". It has brought about some slight progress in the patterns of student enrolment in different disciplines. However, educational reforms have not been quite successful in bring significant changes in the education in terms of quality. Furthermore, several important initiatives have also been undertaken for encouraging the scientific research in Qatar under Qatar Foundation in the form of provision of Qatar National Fund and the Oases of Science and Technology. In contrast to educational domain, research initiatives have begun to play important role for supporting different sectors such as: industry, health, environment, energy and computing. However, despite 
taking all the afore-mentioned initiatives they are still proving to insufficient in bringing considerable changes in the overall picture.

The main problem started when the students began to get motivated towards the disciplines that qualified them for getting sure jobs. Several factors played an active role in formulating students' orientation from the perspective of career choices. The most prominent factor can be their perceptions regarding lack of sense of competence for studying disciplines such as science, mathematics, engineering and technology. Cultural values also played significant role in alienating them from certain professions. Additionally, gender related occupational preferences also performed its role. For example, Qatari culture and their traditions proved to be detrimental for the women's career in general.

In 2004 a survey was run on a sample of 400 Qatari male falling in the age group of 15-19 and 20-24 years (Kaltham Al-Ghanim.2004). The main aim of the study was to investigate the career choices of the young people. On the overall note, the study results reveal negative attitude towards working in the industry sector and getting engaged in professional, technical or handicraft related occupations. At the same time, the findings of the study indicated the Qatari youth's fondness of working in the supervision kind of jobs. Furthermore, the study established a positive correlation between such attitudes of Qatari people with the different socio-cultural factors such as: level of the parent's education, work environment requiring them to wear blue uniforms while working in afore-mentioned professions which contradicted their traditional dress (Thub) and head-dresss (Gatra and Egal).

As mentioned previously, Qatar society also experiences the presence of a strong correlation between the gender and the career choices made by the people. The value system and attitude of the social institutions plays a prominent role in formulating people's preferences towards career choices. It is worth mentioning that they have strong influences on the women's career choices as compared to the male counterpart. In fact, the societal and cultural values are finely embedded in their lifestyle. Qatari society is dominated by patriarchal values, which has determined a list of favored occupation for women. Hence, despite their performance in comparison to men the cultural restrictions start exerting their influence on women right from the stage of making choices regarding their education. In this regard, the study conducted by Kaltham Al-Ghanim (2007) reflects people's opinion that women's abilities are not suitable for certain job types. As there is no specific gender segregation regarding job profiles, family cultural background proves to be the biggest hurdle for women while making their choices of the preferred careers.

Additionally, some of the cultural values strongly inhibit or have barred women's entry into certain disciplines such as engineering. The extent 
of their influence can be imagined from the fact that the University of Qatar did not open registration for women at all for few years. Sulaiman et al. (2010) in a study at Qatar University revealed that the recruitment of the women was the major issues rather than their retention regarding entering into the engineering disciplines. The study findings contract the existing notion regarding in ability of women to participate in certain job types as it shows a gap hole at the educational and societal level rather than their lack of abilities for such disciplines. However, the situation began to change slowly as the society and its value system became more open as a result of the economic developments. This was reflected by the increase in the number of women enrollment in the disciplines that were earlier restricted for them. However, still there are certain families in the society who are still stuck with the old value system.

One of the unpublished study conducted by Ras Gas and Dolphin Energy at the Qatar University in 2009 on over 1000 young Qatari people revealed the lack of self-efficacy is the primary factor formulating their orientation towards educational and career choices. It emphasized that the lack of self-efficacy was restricting for studying certain disciplines such as science, mathematics and engineering. In this context, Yousif et al. (2009) found that the aforementioned disciplines led students to make careers in energy and industry sector. Therefore, revealing that the gaps in the educational setup were the leading to the problems in the labor market.

The prevalent socio-cultural factors also impact students' choices of academic disciplines. For example, they showed that the students' have favorable attitude towards literary disciplines while they are in general reluctant towards studying scientific disciplines such as - mathematics, physics and material sciences in addition to specializations like mechanical and chemical industrial engineering. However, the socio-cultural factors exert a stronger influence on women's career choices than men. This becomes evident from the previously mentioned fact that they come into action during the early stages when women's make their educational choices that ultimately define their career choices. At the same time, Labor Force Statistics (Statistics Authority. Labor force statistics 2011) indicate that the females comprise of the majority of the student registrations (77\%) for higher education especially at Qatar University. Considering the fact that the majority of the students in the higher education are females couples with the societal perceptions that consider women to be unfit for certain job types creates a challenging situation in the existing labor market. Moreover, the statistics also reveals that only one third of the females are active in the labor market (Statistics Authority. Labor force statistics 2011).

Qatar is experiencing the decline and shortage of the number of students and labor force having STEM knowledge and skills. Such a 
situation is pressurizing the existing Qatar economy to make a transition to the knowledge-based economy. Considering the gravity of the prevalent situation Qatar government has set to national vision to transform Qatar's economy to a knowledge-based economy by 2030. For achieving the set goal, the educational system needs enhancement from the perspective of educational methodologies and learning strategies. The new educational system should be capable of attracting or engaging students to study disciplines that will help them in attaining knowledge and skillset required for matching the needs of the changing labor market. Thus, the renewed educational system can contribute towards supporting the national economy.

\section{Research Methodology}

Our research methodology has been influenced from a popular believe that innovative and advanced learning environment will increase the learning performance and improve the attitude of secondary school students towards science subjects. Furthermore, it will also impact their career choice ahead in the future. These arguments haven been based (William Carbonaro, 2005:27-49) study which emphasized that innovative learning environment motivates students to put more effort and expand their performance when they face challenges. Furthermore, innovative learning environment inculcates desire to learn and ability to achieve. Due to this reason, our research is aimed at identifying various new learning possibilities offered by the adoption of innovative and advanced learning environment within the secondary schools. Furthermore, advanced learning environment is based on active learning strategy.

Study Planning and Design: This study was organized at the Center of Advanced Martial located in Qatar University during the academic year 2011/2012. The learning Muddle that applied in the experiment based on a set of interconnected information in materials science provided as a research problem to the students. Within the timeframe of two weeks the study participants conducted the research and laboratory experiments for discovering and identifying the critical variables. Additionally, it enabled them to search practical and innovative solutions for making amendments in the material or changing it to other forms under the supervision of senior researchers. The engagement in the laboratory activities enabled students to learn from different perspectives. For example, it empowered them to become self-educated (independent), gave them hands-on experience of working in teams for verifying their findings and presenting their findings in the form of scientific reports.

The conducted experimental setup tested the applicability of a learning strategy that involved indulging in research activities in advanced learning environment (CAM-QU laboratories). The tested learning strategy 
aimed at enhancing the learning abilities of the students in addition to changing their general attitude towards science. The research based on testing of the learning strategy used following factors as intermediate variables:

Innovative environment (CAM-QU laboratories): This involves transferring a high school student to a non-traditional learning environment. Such a setup will provide students' with the opportunity to think, practice and conduct experiments in advanced scientific labs. Additionally, in the process they will get to interact with the advanced scientific equipment that will provide them exposure to new kinds of research experience.

Active learning strategies such as Problem-solving method: The experiment setup involved the program "I am a Researcher" in which the students are required to solve a given scientific problem. The decision regarding the including the afore-mentioned program was based on the assumption that hands-on experience in resolving research problems can enhance students' motivations to search and investigate the solutions. The educator acted as moderator during this experiment where his/her job was to provide students with some scientific problem, guiding them in using lab equipments followed by observing their progress while ensuring their security at the same time.

Co-operative learning method: During this part of the experimentation the students were asked to work in small groups. Such a setup will enable students to learn working in teams by cooperating with other team members. Apart from developing their sense of teamwork, it will also allow them to understand the benefits of working in teams. For example, learning from the experience of working with others. The teamwork required the students to device solutions and drawing conclusions after they have performed their investigation on the given research problem.

Our research team assumed that if students' participation in an open advanced learning environment under the supervision of a senior researcher would expand their knowledge base. As mentioned previously, during the whole process they will perform various roles, while solving a given research problem such as: active learner, problem solver, self-learner and collaborator while working in teams. The performance of all these activities assumed to bring a positive change in the students' attitude towards science and research. Such a constructive change in the students' attitude will help in developing their sense of self-efficacy and provoking their interest towards studying science in long term. The overall aim of the research experiment is to emphasize the importance of non-traditional teaching methods for enhancing the student learning and improving their knowledge and attitude towards science 
The experimentation setup employed the usage of a pre-posttest instrument to avoid any bias in the study results. For example, for ensuring that the experiment results is free from the affects of the additional variable. The pre-posttest instrument was a suitable test design for measuring the learning outcomes of the experiment especially students' learning performance, their attitude towards science and their sense of self-efficacy. The pre-test instrument was tested with the students in school two days before the initiation of the actual educational experiment. On the other hand, post-test instrument was involved after the termination of educational experiment when students returned to their school.

Study Validity Measures: In order to ensure that study experiment produces valid and reliable results, researchers have taken into account several factors that might impact the study results. This includes various factors that might effects the response of individuals when they get tested for-example age, gender, type of school they study (Omar Al Shaibani, 1971, pp. 183-184). Therefore, we collected all kinds of demographics information from the participating students namely age, educational level (secondary in case of all students), grade (all participants were from Grade 12), academic background of the participants (all participants came from same types of schools with similar learning environment) and finally cultural background (all participating students belong to same nationality, community and even speak same language)

Study Participants: In this study experiment a total of 120 high school students comprises of 51 males and 69 females participated. This sample was randomly selected from 1000 students participated from 23 school who participated in Al-Birag learning program called "I' $\mathrm{m}$ researcher experiment" during 2011/2012 academic year. These randomly selected 120 students were subjected to an educational experience for over 2 weeks in CAM lap located at Qatar University. The participating 120-student sample was divided into 4 groups where each group was further divided into 6 subgroups having 5 students in each of the sub-groups

Reliability and Validity Considerations: As reliability and validity of the used scale or parameter of testing participants is important for producing reliable results and generalizing the findings of the study. Therefore, we tested the validity of the second part of the questionnaire survey, which assessed the student's attitudes towards science and their self-efficacy. We used the coefficient of Cronbach's Alpha as a parameter for examining the internal consistency of questionnaire items. The value of the consistency paramter is between 0 and 1 but our questionnaire showed a consistency value of 0.80 which is $80 \%$. This high value of Cronbach's Alpha shows that measures will give same results even if it is applied to a different sample. 


\section{Study Results}

The study questionnaire consisted of two sections where the first section was focused on accessing the students' ability to gain the knowledge and whether their score meet our expectations. The second part of the questionnaire was based on accessing students' attitude towards research; sense of competence; self-efficacy and their desire to work in groups i.e. team work. The second part of the questionnaire involves five points Likert scale comprises of scales namely strongly agree, agree, neutral, disagree and strongly disagree. The findings of our study have shown that there is a significant improvement of the educational attainment while the student's attitude became positive after the completion of the research. The results are explained below in detail:

Students' learning performance (Knowledge): This assessment is based on the average of correct answers given by the students. We used four point ranking scale namely under score, average score, gained score and excellent score for assessing the results obtained from students. In the testing, we designed as pre-test and post-test so as to examine the differences in the learning performance of the participating students. In order words, pretest and posttest were tools for evaluating acquiring of knowledge by the students. Based on this examination, all the students were divided into four groups and Table 2 shows the students' learning achievement based on gender.

The comparison between the results obtained from the pretest and posttest clearly showed that there has been improvement in the students' knowledge about the science. Additionally the results have also shown that males achieved better results compared to females in terms of gaining scientific knowledge. For-example, mean of the correct answers given by males were 3.22 in contrast to females which was only 2.88 (See Table 1).

[Table 1: Students learning achievement based in gender]

\begin{tabular}{|c|c|c|c|c|c|}
\hline & Gender & \multicolumn{3}{c|}{ Statistic } & Std. Error \\
\hline Pretest & FEMALE & 51 & Mean & 2.57 & 0.178 \\
\hline & & & Std. Deviation & 1.269 & \\
\hline & MALE & 69 & Mean & 2.70 & 0.139 \\
\hline & & & Std. Deviation & 1.154 & \\
\hline & Gender & $\mathrm{N}$ & & Statistic & Std. Error \\
\hline Posttest & FEMALE & 51 & Mean & 2.82 & 0.150 \\
\hline & & & Std. Deviation & 1.072 & \\
\hline & MALE & 69 & Mean & 3.22 & 0.150 \\
\hline
\end{tabular}

On comparing the students' learning performance among four different groups, it was found that first and fourth group students achieved the score as per our expectations. Therefore, group 1 and group 4 students 
showed remarkable improvement by scoring excellent scores which was $48 \%$. The group 2 score can be evaluated as $27 \%$ as excellent while a significant population I.e. $50 \%$ of them underscored. Similarly in group 3, about $19 \%$ secured as excellent while significant number i.e. $47 \%$ scored as "average".

The comparison between the averages of the all four groups was testing through the analysis of variance test (see Table 4). This test has clearly shown that there is a indication for the axes of the three where the values of the significance of the axes in the order are 0.004 and 0.005 and 0.000 which is smaller than the value of the significance test 0.05 , so we reject the null hypothesis and accept the alternative hypothesis (ie, there are differences between the averages of students answers according to the group.

Student's attitude towards Science: The questionnaire examining students attitude towards science, self-efficacy and desire to learn have been organized as follows: Group 1: I (Attitude towards science), Group 2: (Selfefficacy) and Group 3: (desire to learn). These three groups are explained as follows: Group 1 examines the students' desire to participate in various science related learning activities, students' participation in the laboratory work, knowledge discovery and attitude towards searching new knowledge. Group 2 examined sense of confidence among students to acquire new research skills and abilities to invest new knowledge and information. Group 3 examines if the student experienced fun while participating in the experiment and do they feel interested while carrying out various activities in the laboratories.

[Table 2: Correlation analysis]

\begin{tabular}{|c|c|c|c|}
\hline Correlation analysis & Mean & Std. Deviation & N \\
\hline Attitudes towards science & 4.32 & 0.647 & 120 \\
\hline Self-efficacy & 4.19 & 0.738 & 120 \\
\hline Desire to learn & 3.65 & 0.684 & 120 \\
\hline
\end{tabular}

As we see above there was a noticeable improvement in the 3 axes. Attitudes towards science and Self-efficacy achieved better results.

We noticed from the data that the relationship between the 3 axes direct correlation (positive correlation) and statistically significant is very high (less than or equal to 0.001) and find that the axes (Attitudes towards science) and (Self-efficacy) have a strong positive correlation relationship (.759), but the axes (self-efficacy) and (desire in learning) the correlation was weak (0.481). (See Table 3). 
[Table 3: Correlation analysis]

\begin{tabular}{|c|c|c|c|c|}
\hline & & $\begin{array}{l}\text { Participation } \\
\text { in the lab }\end{array}$ & $\begin{array}{l}\text { Participation } \\
\text { in the program }\end{array}$ & $\begin{array}{l}\text { Desire to } \\
\text { participate }\end{array}$ \\
\hline \multirow{2}{*}{$\begin{array}{l}\text { Attitudes towards } \\
\text { science }\end{array}$} & Pearson Correlation & 1 & $0.759 * *$ & $0.481 * *$ \\
\hline & Sig. (2-tailed) & & 0.000 & 0.000 \\
\hline & $\mathrm{N}$ & 120 & 120 & 120 \\
\hline \multirow{2}{*}{ Self-efficacy } & Pearson Correlation & $0.759 * *$ & 1 & 0.423 \\
\hline & Sig. (2-tailed) & 0.000 & & 0.000 \\
\hline & $\mathrm{N}$ & 120 & 120 & 120 \\
\hline \multirow{3}{*}{ Desire to learn } & Pearson Correlation & $0.481 * *$ & 0.423 & 1 \\
\hline & Sig. (2-tailed) & 0.000 & 0.000 & \\
\hline & $\mathrm{N}$ & 120 & 120 & 120 \\
\hline
\end{tabular}

Correlation is significant at the 0.01 level (2-tailed

Chi-square test of independence: Null hypothesis: the group does not depend on the gender (gender and the group are independent). The alternative hypothesis: Group depends on the gender (no relationship between the group and gender). Chi-square value equal to 3.25 degree of freedom of 3 and less value to the significance level is 0.355 . Since the significance level is 0.355 greater than the significance level testing 0.005 . Therefore, we accepted the null hypothesis (the group does not depend on the gender).

Student's desire to Learn: The results have clearly shown an improvement in the students' attitudes towards learning. The results based on the differences between pre-test and post-test has shown that percentage of the students' who agreed as "strongly agree" increased from $43 \%$ to $52 \%$. Interestingly, percentages of the students settled with "agree" declined from $48 \%$ to $37 \% /$. Students those agreed as "neutral" increased from $9 \%$ to $11 \%$ but still 1\% students mentioned, "Strongly disagree"

Students' Self-efficacy: The finding shows an improvement in the students' self-efficacy therefore; students became confident about their research skills. It was found that the percentage of students who agreed as "strongly agree" increased from $22 \%$ to $26 \%$ and the percentage settled with "agree" increased from $38 \%$ to $42 \%$. Interestingly, students who agreed as "neutral" decreased from $27 \%$ to $23 \%$ and $10 \%$ of the students still opted as "disagree" while none answered as "strongly disagree".

\section{Conclusion}

As the conclusion of this present study, it was found that advanced learning environment resulted in the improvement of the students' ability to acquire and retain new knowledge. Furthermore, study also concluded that advanced learning environment had direct positive impact on students' attitude towards research and students gained positive attitude towards work as well. After engaging in the advanced learning environment and related 
research activities, secondary school students have shown desire to learn and improve their self-efficacy and self-confidence. This shows that regular engagement of students with the advanced learning environment would certainly motivate student towards learning, participating and showing interest about science. In terms of performance of our experiment, study results have clearly shown that this experiment was successful in improving the knowledge of the high school students and their attitudes towards scientific research. Furthermore, experiment was successful in enabling students to acquire new research skills and at the same time increasing the self-efficacy among students. The results showed that the learning based on research activities enhance students' ability for learning.

\section{References:}

Abdalla, I.A. (1988). Work environment, job structure and behavior orientation as predictors of skill-utilization in Kuwait: The moderating effect of ability. Genetic, Social and General Psychology Monographs114 (2): 1973-89.

Abdalla, I.A. (1991). Social support and gender responses to job stress in an Arab culture. In Perrewe, P.L. (Eds.). Journal Of Social Behavior and Personality6 (7): 273-88.

Areepattamannil, S., Freeman, J. G., \& Klinger, D. A. (2011). Influence of motivation, self-beliefs, and instructional practices on science achievement of adolescents in Canada. Social Psychology of Education: An International Journal, 14(2), 233-259

Bandura, A. (1977). Self-efficacy: Toward a unifying theory of behavioral change. Psychological Review, 84, 191-215.

Bandura. A, Claudio Barbarnelli, Gian Vittorio Caprana and Cancetta Pastorelli.(2001).Self - Efficacy Beliefe as Shapers of Children's Aspirations and career Trajectories, Child Development , January/ Februray , Volume 72, Number 1,Pages 187-206.

Bandura, A. (1994). Self-efficacy. In V. S. Ramachaudran (Ed.), Encyclopedia of human behavior (Vol. 4, pp. 71-81). New York: Academic Press. (Reprinted in H.Friedman [Ed.], Encyclopedia of mental health. San Diego: Academic Press, 1998).

Eylem YILDIZ1, Ercan AKPINAR2, Bülent AYDOĞDU1, Ömer ERGINN, 2006. Science Teachers' Attitudes towards Aims of the Science Experiments, Journal of Turkish Science Education ,v.3, n.2, December 2006, pp.2-18

Gaad, E. (2004). Pre-service teachers attitudes towards a career in special education in the United Arab Emirate. College Student Journal. BNET Network. Retrieved on August 24, 2008, from 
Hattie, J. (2009). Visible learning: A synthesis of over 800 meta-analyses relating to achievement. New York, NY: Taylor \& Francis.

Ikhlas A. Abdalla, (1995) "Arab business administration students: attributes and career decision making self-efficacy expectations", International Journal of Career Management, Vol. 7 Iss: 6, pp.27 - 35

Jerry A. Jacobs, David Karen and Katherine McClelland.(1991). The Dynamics of Young Men's Career Aspirations, Sociological Forum , Vol. 6, No. 4 (Dec., 1991), pp. 609-639.

J.E. Myburgh, (2005) "An empirical analysis of career choice factors that influence first-year Accounting students at the University of Pretoria: A cross-racial study", Meditari Accountancy Research, Vol. 13 Iss: 2, pp.35 48.

Jonathan Osborne , Shirley Simon \& Sue Collins (2003): Attitudes towards science: A review of the literature and its implications, International Journal of Science Education,25:9, 1049-1079

Kaltham Al-Ghanim. (2004). Attitude of Qatari Youth towards Industrial technical works in State of Qatar, annuals of arts and social science, Kuwait University, volume (24).

Kaltham Al-Ghanim, 2007. Obstacles that reduce women share of leadership positions in Qatari society, Supreme Council for Family Affairs, Qatar.

L. R. McNarry, S. O'Farrell ,1971.Students Reveal Negative Attitudes toward Technology, American Sociological Association, Science , New Series, Vol. 172, No. 3987 (Jun. 4, 1971), pp. 1060-1061

Martin, M., Mullis, I., Foy, P., \& Stanco, G. (2011). Timss 2011 international results in science. TIMSS \& PIRLS International Study Center, Lynch School of Education, Boston College Chestnut Hill, MA, USA Boston: Boston College.

Novak, J. M. (2001). Invitational education. Bloomington, Ind.: Phi Delta Kappa Educational Foundation.

Qatar University , Office of Institutional Research and Data Warehouse, Fact book 2010 - 2011 Pajares, F. (1997). Current directions in self-efficacy research. In M. Maehr \& P. R. Pintrich (Eds.). Advances in motivation and achievement (Vol. 10, pp. 1-49). Greenwich, CT: JAI Press

Sulaiman, Noor Fauziah; AlMuftah, Hend, 2009. A Qatari Perspective on Women in the Engineering Pipeline: An Exploratory Study, European Journal of Engineering Education,v35 n5 p507-517 Oct 2010

Labor force statistics, 2011., Statistics Authority Bulletin, Stat of Qatar Michael O. Martin, Ina V.S. Mullis, Pierre Foy, and Gabrielle M. Stanco. 2011. Trend in International Mathematics and Science Study (TIMSS ): International Results in Science, International Study Center, Lynch School of Education, Boston College Chestnut Hill, MA, USA, and International 
Association for the Evaluation of Educational Achievement (IEA) IEA Secretariat Amsterdam, the Netherlands.

William Carbonaro, 2005. Tracking, Students' Effort, and Academic Achievement, American Sociological Association, Sociology of Education, Vol. 78, No. 1 (Jan), pp. 27-49.

World Bank Report, 2005 about the secondary education was under this title: "expand opportunities for young people and building competencies: a new agenda for the future".

Ziad Said. (2011). 'Qatari Students' Interest in Attitudes toward Science: the Impact of the Educational Reform on Science Education in Qatar. Qatar Foundation Annual Research Forum Proceedings: Vol. 2011, AHO4. DOI: 10.5339/qfarf.2011.aho4.Published online: 14 Dec 2011.

Yousif, A., Sharif, K; Allen, N., Alghazo, E., \& Zepp, R. (2009). Qatari youth perceptions and expectations of the energy and industry sector. An unpublished study sponsored by Dolphin Energy and RasGas, with support from Qatar Petroleum and Qatar University Office of Research. 